\title{
A "ARTE" LULIANA COMO AUTORIDADE ALTERNATIVA*
}

Anthony Bonner**

SÍNTESE - As obras de Raimundo Lúlio são famosas pela ausência de citação de autoridades. 0 presente artigo aventa que Lúlio desejava fundamentar a Arte, a qual, segundo sua convicção, lhe fora dada por Deus, como uma autoridade alternativa, e que esta poderia então tornar-se o ponto focal de uma comunidade textual, dedicada ao estudo do seu método e mensagem.
ABSTRACT - Llull's works are notable for their lack of citation of authorities. The article suggests that Llull wished to establish the Art, which he was convinced had been given to him by God, as an alternate authority, and that this could then become the focal point of a textual community dedicated to the study of his method and message.

$\mathrm{Na}$ obra de Raimundo Lúlio ocorre algo que pode parecer chocante. Num autor medieval dedicado inteiramente - quase se poderia dizer monoliticamente à pregação ad extra et ad intra da fé cristã, encontramos uma falta surpreendente de referências ao aparato desta fé. Talvez a melhor maneira de ver até que ponto esta situação é anômala e inclusive dramática, é questionar-nos sobre o que saberia um homem vindo de outra civilização a respeito da cristandade e da cultura

* Gostaria de agradecer a Lola Badia, Josep Maria Ruiz Simon e a Lluís Cabré, que muito amavelmente leram este artigo, e fizeram observaçōes e correçōes muito úteis.

* Vice-reitor da Maioricensis Schola Lullistica.
Abreviaturas utilizadas
ATCA = Arxiu de Textos Antics (Barcelona).
EL $\quad=$ Estudios Lulianos (Palma) 1957-1990.
ENC = Els Nostres Clàssics (Barcelona).
MOG = Raymundi Lulli Opera omnia, ed. I. Salzinger, 8 vols. (Magûncia, 1721-41) citado as- sim: MOG I, 434 = Int. vii, 1 onde 434 refere-se à paginação contínua da reimpres- são (ed. Stegmüller, Frankfurt, 1965), e o último número refere-se à primeira página da sétima numeração intema da edição original.
NEORL = Nova Edició de les obres de Ramon Llull (Palma, 1991 e ss.)
ORL $\quad=$ Obres de Ramon Llull, edició original (Palma, 1906-50).
OS $\quad=$ Obres Selectes de Ramon Llull (1232-1316), ed. A. Bonner, 2 vols. (Palma, 1989).
ROL $\quad=$ Raimundi Lulli Opera Latina (Palma e Turnhout, 1959 e ss.)
SL $\quad=$ Studia Luliana (id) (a partir de 1991. Antes El).
$\otimes \quad=$ Assim assinalaremos a tradução feita por mim - o tradutor deste artigo - de alguns trechos em catalão antigo, cuja tradução não consta no artigo original do prof. Bon- ner por tê-lo escrito em catalão (Esteve Jaulent). 
ocidental do século XIII se só tivesse tido acesso à imensa maioria ${ }^{1}$ da vasta produção do beato (cerca de 265 obras). Saberia, e isto com grande insistência, tudo o que se poderia deduzir dos artigos da fé: a existência de um Deus ao mesmo tempo unitário e trinitário, a Encarnação, a Virgem Maria, a paixão e morte de Jesus Cristo, a ressurreição, etc. ${ }^{2}$ Também encontraria preceitos e orações cristãs como os dez mandamentos, os sete sacramentos, os sete dons do Espírito Santo, o Pater noster ${ }^{3}$ etc. De citações de autoridades, praticamente só encontraria as três seguintes, que verá repetidas também com certa insistência: (1) "podendo-se demonstrar a nossa fé, perder-se-ia o mérito, ${ }^{4}(2)$ "se não credes, não entendereis" ${ }^{\prime 5}$ e (3) "ama Deus teu senhor, com todo teu coração, com toda a tua alma, com todo teu pensamento e todas as tuas forças" ${ }^{\prime \prime}{ }^{6}$ sem poder descobrir nem tão-somente que a primeira é de um papa (Gregório o Grande), e as outras duas da Bíblia. Até poderia percorrer a grande maioria das obras lulianas sem saber que existe algo como uma Bíblia, nem autoridades doutrinais como os santos Padres. Já nem falemos deste espesso bosque narrativo da história da fé e das vidas dos santos que proporcionaram tantos exempla aos escritores da Idade Média. Poderíamos percorrer igualmente a imensa maioria das obras do beato sem encontrar referência alguma à cultura escrita que a envolvia, e às questões que todos discutiam e comentavam nas obras teológicas, filosóficas e literárias. Este visitante, após assimilar tantas obras lulianas, talvez se encontraria um pouco perplexo diante de algo tão ahistórico, abstrato, descontextualizado e autoreferencial. ${ }^{7}$ Em compensação - e é um fato que visto deste ponto de vista chama poderosa atenção - este homem poderia reconstruir bastante bem o funcionamento da sociedade contemporânea, ${ }^{8}$ até melhor que nas obras da grande maioria dos outros teólogos e filósofos de seu tempo. Mas esta sociedade, por muitas cenas de família, de ricos burgueses, de prelados, de cavalheiros, de prostitutas às portas das cidades e dos mercados, de ermitões e

1 Digo "imensa maioria" porque, naturalmente, há algumas exceções, que parecem justificar-se como concessões a uma estratégia do momento. Pense-se, por exemplo, nas obras parisienses dos anos 1309-1311, dedicadas a combater o averroismo. Das outras duas categorias - as citações bíblicas nos sermões dos anos 1304-5, e os exemplis do Llibre de les bèsties - trataremos mais adiante.

2

Cf. a bibliografia citada em OS I, p. 177-9, n. 3 e 7.

Cf. OS II, p. 205 n. 87, e as obras e introduções do ROL XV.

É citado conforme a versão dada por Raimundo Lúlio no Desconhort, XXV. O original diz Fides non habet mentum, cui humana ratio praebet experimentum, e é de Gregório, o Grande, Homiliae in Evangelia, 26 (PL 76, 1197).

Nisi credideritis, non intelligetis, Isaias, 7, 9.

6 Citamos conforme o texto do Llibre de virtuts e de pecats, NEORL I, 10. O original, Dilige dominum Deum tuum toto corde tuo, et tota anima tua et tota mente tua ac totis viribus tuis, encontra-se em Deut. 6, 5, e repetido em Marc. 12, 30 e Luc. 10 27. Veja-se sobre este ponto o estudo importante de Jordi Gayà, El conocimiento teológico, como precepto, según Ramón Llull, EL 18 (1974), p. 47-51.

7 O próprio Lúlio parece consciente desta crítica. No Liber de praedicatione (ROL IV, 11) diz: "Sed antequam ulterius procedamus, volumus nos de aliquibus excusare, de quibus non intendimus pertractare. Et ista sunt, de quibus nullam faciemus mentionem, videlicet auctoritates, historiae, miracula sanctorum, rogationes et etiam interpretationes. Ratio huius est, quia ista possunt in divina pagina reperiri."

Com base em passagens do Libre de contemplació, da Doctrina pueril, do Blaquema, do Fèlix, do Arbre de ciència, do Phantasticus, e algumas poesias. 
de discussões perto do rio Sena que tivesse, continuaria sendo uma sociedade sem textos e praticamente sem tradições.

Para entender até que ponto esta situação é anômala, precisamos situar-nos no contexto da Idade Média. No que diz respeito ao pensamento e à literatura, poder-se-iam caracterizar os dois séculos e meio que vão do 1050 ao 1300 como uma época de retextualização, em quatro sentidos: (1) da transição de uma sociedade quase completamente oral à outra na qual a palavra escrita tinha um lugar privilegiado; ${ }^{9}$ (2) da recuperação de textos, sobre tudo de filosofia e ciência grega e árabe; e (3) da produção de novos textos, e a formação, durante estes séculos, de uma nova cultura européia, tanto literária como filosófica e teológica; (4) e da organização de universidades como centros codificadores das tarefas intelectuais e de formação de uma classe clerical para a qual a escrita era a sua ferramenta profissional. $^{10}$

Antes de seguir adiante, outros dois aspectos desta retextualização medieval precisam ser comentados. O centro - e modelo - dos estudos medievais era a teologia, dedicada a compreender e comentar a sacra pagina, com a ajuda dos escritos dos santos Padres. Mas o fato de conterem uma série de aparentes contradições impelia, não só a técnicas características de interpretação, mas também a uma progressiva fragmentação do estudo, e sobretudo da pedagogia, em multidão de "questões" suscitadas por estas contradições aparentes. Com a finalidade de apoiar e facilitar o seu estudo, procuraram-se as "sentenças" dos santos Padres sobre cada uma destas "questões", a mais famosa sendo a de Pedro Lombardo. Destarte, no ensino predominaram não as leituras seqüenciais dos textos básicos, mas as de florilégios e compilações não somente de sentenças, mas também de receitas espirituais, de decisões canônicas, de exempla para os pregadores, de vidas de santos, etc. ${ }^{11}$ Esta fragmentação pedagógica e intelectual acentuou-se ainda mais com a formação universitária medieval básica, que consistia, como se sabe, nas quaestiones disputatae.

O segundo aspecto da retextualização medieval radica em que, pela sua origem no estudo da sacra pagina, ganhou um teor essencial de "trabalhos de comentário". Basta olhar para a enorme produção de comentários de São Tomás ${ }^{12}$ sobre a Biblia, Aristóteles, Boécio e Pedro Lombardo, para entendermos a sua importância. Era o único modo de absorver os textos novos e uni-los aos outros.

9 Este lugar privilegiado era algo que a civilização ocidental não tinha conhecido desde a época helenística. Com relação à transição da cultura oral a uma escrita, mas que conserva um residuo oral, veja-se Walter J. Ong, "Orality, Literacy, and Medieval Textualization," em New Literary History 16 (1984-5), 1-12, bem como também seu livro, Orality and Literacy. The Technologizing of the Word (Londres, 1982).

11 M.-D. Chenu, La théologie au douzième siècle (Paris, 1976), p. 352. Cf. também The Cambridge History of Later Medieval Philosophy (Cambridge, 1982), p. 17. 
Essa retextualização conseguiu que o ensino universitário medieval se baseasse exclusivamente nos auctores. Em gramática, Prisciano e Donato; em retórica, Cícero; na dialética, Aristóteles, Porfírio e Boecio; na medicina, Galeno, Constantino o Africano e Avicena; em direito canônico, Graziano; em teologia, como vimos, a Bíblia e os santos Padres reunidos nas Sentenças de Pedro Lombardo. ${ }^{13}$ Todavia, o que resulta difícil compreender ao estudioso moderno, é que tipo de auctoritas possuíam aqueles auctores. Em teoria, não podiam errar, nem contradizer-se, nem seguir um plano defeituoso, nem estar em desacordo com outro. Digo "em teoria" porque, de fato, em certos campos como a medicina, existiam fortes discussões entre os seguidores de uma ou outra autoridade, e muitos dos desentendimentos originavam-se justamente nos temas das quaestiones disputatae universitárias. Mas a necessidade de que dominasse uma autoridade era tão forte que os glosadores e os comentadores por vezes tinham de fazer verdadeiros malabarismos na exposição a fim de acomodar a letra do texto à verdade aceite, ou para fazer concordar duas autoridades aparentemente contraditórias. ${ }^{14}$ Esta atitude impregnava toda a produção filosófica e teológica medieval. Ser original, não tinha nenhum valor; ${ }^{15}$ os pensadores mais prestigiosos só buscavam o modo mais adequado de unir suas auctoritates e resolver as quaestiones que a sua leitura suscitava.

É justamente por este motivo que os textos escolásticos apresentam com freqüência cadeias de citações de auctores a fim de justificar uma ou outra postura. Era, portanto, um mundo intertextual num sentido muito mais direto que o que aporta hoje a crítica moderna; estava, com efeito, baseado na intertextualidade, que constituía a sua justificação e razão de ser.

Visto isto, é claro que o contraste com Raimundo Lúlio não podia ser mais chocante. Durante anos pensou-se - e neste verbo reflexivo impessoal me incluo a mim mesmo - que Lúlio assim fazia para fugir das táticas tradicionais da apologética, sobretudo da dominicana, que imperava na Coroa de Aragão. Aqueles procedimentos, habituais na época - Lúlio com toda certeza já o tinha percebido por ocasião da famosa disputa de Barcelona de $1263,{ }^{16}$ e possivelmente pela Pugio fidei de Ramón Martí, obra muito obsessionada em acabar com cada auctoritas judia sobre cada questão ${ }^{17}$ - só levavam a argumentações intermináveis sobre a interpretação dos textos. Ele mesmo no-lo diz:

13 A. J. Minnis, Medieval Theory fo Authorship. Scholastic literary attitudes in the later Middle Ages (Londres, 1984), p. 13. Minnis, op. cit., p. 36, e M.-D. Chenu, op. cit. na nota 11 acima, p. 351 e ss.

15 A discussão clássica da relação obra/autor na Idade Média encontra-se em C. S. Lewis, The Discarded Image (Cambridge, 1964), p. 210 e ss.

16 Cf. os dois livros de Robert Chazan: Daggers of Faith. Thirteenth-Century Christian Missionizing and Jewish Response (Berkeley/Los Angeles, 1989), e Barcelona and Beyond. The Disputation of 1263 and Its Aftermath (Berkeley/Los Angeles, 1992).

17 Cf. Eusebi Colomer, "El pensament de Ramon Llull i els seus precedents històrics com a expressió medieval de la relació fe-cultura", Fe i cultura en Ramon Llull, "Publicacions del Centre d'Estudis Teològics de Mallorca" II (Mallorca, 1986), p. 9-29, e meu trabalho, "L'apologètica de Ramon Martí i Ramon Llull davant de l'Islam i del judaisme", El debat intercultural als segles XIII $i$ XIV. Actes de les I Jomades de Filosofia Catalana, Girona 25-7 d'abril de 1988, "Estudi General" 9 (Girona: Col-legi Universitari, 1989), p. 171-185. 
"Iste liber factus fuit hac intentione, videlicet, ut Christianus et Saracenus per rationes, non per authoritates, ad invicem disputarent; nam authoritates calumniantur ratione diversarum expositionum." ${ }^{18}$

Em outra obra explica-se ainda mais claramente:

"Moltes actoritats de sans pot hom applicar a aquestes probations que nós entenem donar. E car neguna auctoritat vera no pot éser contra raó necessària, per so no curam tractar en aquest tractat d'auctoritats, com sia assò que auctoritats pusca hom espondre en diverses maneres e aver d'éles diverses oppinions, per les quals se multipliquen paraules e esdevé l'enteniment en confusió, adoncs com los uns hòmens disputen ab los altres per auctoritats." 19

E, finalmente, a sua declaração mais lapidária:

"Disputar per auctoritats no ha reps." ${ }^{20}$

Como se pode apreciar, as três citações têm a ver com o "disputar"; mas, mesmo limitando-nos ao campo da apologética, resultam ser declarações programáticas bastante fortes e totalmente fora de uso no seu tempo. ${ }^{21}$ Nos capítulos sobre 0 mesmo tema do Llibre de contemplació Lúlio chegou a dizer que com gente de entendimento grosso é mais vantajoso discutir "ab auctoritats e ab miracles de sants" ("com a ajuda da autoridade e dos milagres dos santos") do que "ab raons ni ab arguments naturals" ("com razões ou argumentos naturais"), dado que o homem "neci de gros enginy pus prop és de fe que de raó." ("ignorante e de inteligência pesada está mais perto da fé que da razão." $)^{22}$

Contudo, esta oposição entre argumentos de autoridade e de razão, tão desfavorável para os primeiros, parece esconder algo mais do que uma simples tática no confronto com muçulmanos e judeus. Uma passagem da Doutrina pueril pode darnos uma primeira pista:

18 Disputatio Raymundi christiani et Homeri saraceni (MOG IV, 476 = Int. vii, 46).

19 Disputació de cinc savis, ATCA 5 (1986), 33-34. "Muitos argumentos de autoridade de santos podeniam-se aplicar a estes que nós damos. Todavia, como nenhuma verdadeira autoridade pode ir contra as razões necessárias, não pretendemos cujdar neste tratado delas, até mesmo porque os argumentos de autoridade podem ser expostos de diversas maneiras e se podem ter deles diversas opiniões, o que multiplica as palavras e o entendimento entra em confusão quando os homens disputam uns com os outros baseando-se nos argumentos de autoridade." $\otimes$

Proverbis de Ramon, 248, 5 (ORL XIV, 271). "Não existe descanso na disputa por argumentos de autoridade." $\otimes$

21 São Tomás também afirma no começo da Summa contra gentiles (cap. 2) que por falta de acordo entre muçulmanos, pagäos, judeus e hereges sobre as autoridades, necesse est ad naturalem rationem recurrere, cui omnes assentire coguntur, mas na continuação põe centenas de citações no texto da obra.

Cap. 187, 10 e 12 (OE II, 548). Cf. Marcel Salleras, "L'"art d'esputació de fe"en el Llibre de contemplació en Déu", El debat intercultural als segles XIII $i$ XIV. Actes de les I Jornades de Filosofia Catalana, Girona 25-7 d'abril de 1988, "Estudi General" 9 (Girona: Col-legi Universitari, 1989), p. 187-197, e especialmente p. 191. No capitulo sobre "disputar" na Art demostrativa (OS I, 391) Lúlio chega a dizer que: "Em toda disputa convém que se dispute por autoridades, se N (= vontade amando o desamando, entendimento ignorando, memoria esquecendol), ou por razöes, se E I (= vontade amando ou desamando, entendimento entendendo, memória lembrando)." 
"No som en temps de miracles, cor la devoció era major de convertir lo món en los Apóstols que no és ara en lo món en què som; ne rahons fundades sobre actoritatz no reeben los infeels; donchs convinent és a convertir los infeels lo Libre de demostracions e la Art de atrobar veritat, la qual lus sia mostrada, per tal que ab ella los combata hom lur intel-ligència, per ço que congan e amen Déu. ${ }^{\text {.23 }}$

Esta equiparação - que poderia ser chamada metodológica - entre milagres e autoridades, aparece reforçada numa passagem do Blaquerna, onde a Fé explica que

"Temps es vengut que no volen reebre auctoritats de sants, ni miracles no són per los quals eren inluminats los innorants de mi e de ma ssor. E per ço cor les gents requeren rahons e demonstracions necessàries, vayg a mon frare, qui es poderós, per la virtut de Déu, a provar los .xiiii. articles.

Respòs Blaquerna dién que fe hi perdria sos mèrits sill enteniment demostrava los articles per los quals fe ha inluminament a creure contre enteniment. Mas Fe dix a Blaquerna que no era cosa cuvinent que la principal rahó per què hom vol convertir los infeels, sia per ço que la fe, ne sia occasió de major mèrit. - Ans cové que sia secundària entenció, e que la principal entenció sia que Déus sia conegut e amat...." ${ }^{24}$

Temos nestas linhas um nexo de idéias que pode começar a esclarecer as coisas. De um lado, milagres e autoridades pertencem ao campo da fé, com a qual o homem pode ter um mérito maior, como explica Blaquerna numa paráfrase da primeira das três citações que repete insistentemente. ${ }^{25}$ Por outro, contamos com as "razões", que permitem que Deus seja conhecido e amado. Nesta oposição entre fé e razão, o conteúdo da fé é denominado, na terminologia típica luliana, uma "segunda intenção", enquanto que será a razão a que permitirá conhecer e amar a Deus, e portanto alcançar a "primeira intenção". Confesso que esta declaração me surpreendeu quando a li pela primeira vez. Mas logo percebi que esta é uma postura doutrinal amplamente discutida e defendida por Raimundo Lúlio. Explica-a em muitas obras, mas talvez a sua declaração mais clara a encontramos numa Disputació que escreveu sobre as Sentenças de Pedro Lombardo, ${ }^{26}$ onde se lê que "Homo principaliter no sit creatus ad se, nec per consequens ad habendum meritum per

23 Cap. 83 (ed. Gret Schib, p. 197). "Nossos tempos não são propicios aos milagres, pois a devoção por converter o mundo era maior no tempo dos Apóstolos que nos de hoje; e o infiéis não aceitam argumentos baseados na autoridade; portanto, para converter os infiéis é conveniente o Livro de demonstraçöes e a Arte de encontrar a verdade, que os deve ser mostrada a fim de que com ela se lute contra a sua inteligência até que conheçam e amem a Deus." $\otimes$

24 ENC 50-51, p. 217. "Chegou o tempo em que [os sarracenos] não aceitam a autoridade dos santos, nem os ignorantes de minha [Fé] e de minha irmä [Verdade], a luz dos milagres. Por isto, como as pessoas querem argumentos e demonstrações necessárias, vou junto ao meu irmão [Entendimento], que é poderoso, e com a ajuda de Deus, provarei os treze artigos. Respondeu Blaquerna dizendo que a fé perderia o seu mérito se o entendimento demonstrasse os artigos mediante os quais a fé ilumina para que acreditemos contra razão. Contudo, a Fé disse a Blaquema que não era conveniente que o principal motivo pelo qual se quer converter os infiéis, seja justamente que com fé haja major mérito. - É melhor isso ser uma "intenção segunda", e que a principal intenção consista em que Deus seja conhecido e amado..."® Cf. a nota 4 acima. É a primeira das três citaçỏes que Lúlio repete sempre.

26 Trata-se da Disputatio eremitae et Raymundi super aliquibus dubiis questionibus Sententiarum Petri Lombardi. 
fidem, imo principaliter est creatus ad intelligendum, diligendum et recolendum Deum. ${ }^{.27}$ Esta vertente, em certa maneirá egoísta da fé (quer dizer, que leva o homem a se preocupar apenas com a sua própria salvação), é bem apresentada no $L i$ vro do amigo e do Amado:

"[L'amic dix a l'amat] que fortment se maravellava de les gents, qui tan poch l'amaven, e1 coneixien $e-1$ honraven... E-1 Amat li respòs dient que ell havia pres molt gran engan en ço que havia creat home per ço que-n fos amat, conegut, honrat. $\mathrm{E}$ de mill hòmens, los çent lo temien e-l amaven tant solament; e de los çent, los -xc- lo temien per ço que no-ls donàs pena, e los - $\mathrm{x}$ - l'amaven per ço que-lls donàs gloria. $\mathrm{E}$ no era quaix qui-l'amàs per sa bonea e sa nobilitat. ${ }^{28}$

Este conhecido trecho lembra a história da santa mulher muçulmana, Rabi'a, que passeava com um tronco na mão e um balde de água na outra, a fim de queimar o Paraíso e extinguir os fogos do inferno, para que a humanidade amasse a Deus desinteressadamente.

Aqui conviria fazer um pequeno inciso para explicar que esta postura do beato nada tem a ver com um racionalismo que começasse por opor a fé à razão, para depois inclinar-se em favor da segunda. Lúlio insistiu sempre em que ambas devem ajudar-se mutuamente, e que muito embora a razão seja a ferramenta principal para alcançar a "primeira intenção", de fato nenhuma das duas poderia subir até as esferas divinas sem a outra. Por isso, a passagem antes citada do Blaquerna termina dizendo:

"... e que enteniment pusca husar de sa virtut per ço que jo-n sia major e en pus alt grau. Cor aytant con l'enteniment pot pujar més ha enssús per entendre los articles, d'aytant pusch yo sobre puyar més a enssús sobre l'enteniment, e creu ço que ell no pot entendre. $" \otimes{ }^{29}$

O que Lúlio explica com a bela imagem do azeite da fé que flutua por sobre a água do entendimento, e quanto mais sobe a segunda, ainda mais subirá a primeira. ${ }^{30}$

27 MOG iv, 229 = Int. iv, 5. Afirmações semelhantes encontram-se no Liber de demonstratione per aequiparantiam (ROL IX, 221), e, mais amplamente argumentadas no Desconhort, vv. 25-6. Em Félix, cap. 79 (OS, 261), refere-se a um outro lado da questão, ao queixar-se de que, se for verdadeiro o que diz um clérigo, "daí seguir-se-ia que o entendimento humano não pode nem deve entender a Deus, justamente quando foi criado para que o entenda. Como poderia entender estas coisas mundanas, se năo foi principalmente criado para entendê-las? $\mathrm{E}$ o mesmo poder-se-ia dizer da memória e da vontade."

V. 218 (ENC 74, p. 60). "[Disse o amigo ao Amado] que muito se admirava de que tão poucos o amassem, o conhecessem e o honrassem conforme merecia a sua dignidade. $\mathrm{E} \circ \mathrm{Amado}$ disse-lhe que ficou decepcionado com o homem que criara precisamente para que o amasse, conhecesse e honrasse. Lamentou-se de que entre mil homens apenas cem o temian ou amavam. Que dos cem, noventa o temiam pelo castigo, e dez o amavam esperando, assim, receber glória. E que ninguém o amava por sua bondade e nobreza." Cf. Raimundo Lúlio, Livro do amigo e do Amado, "Introdução, tradução e estudos de Esteve Jaulent", Edições Loyola, São Paulo, 1989, n. 217 à p. 100.

$\otimes$ "... e que o entendimento possa elevar-se por sua força a fim de que eu [é a Fe que ainda fala] seja mais poderosa e em um grau mais elevado. Pois, tanto quanto o entendimento possa subir mais acima para entender os artigos, poderei eu ultrapassar por cima o entendimento e acreditar o que não pode entender."

30 Ars generalis ultima, ROL XIV, 276, e Liber de ascensu et descensu intellectus, ROL IX, citado por Eusebi Colomer, "El pensament..." (cf. n. 17 acima), p. 28. 
Se nesse trecho é o entendimento que ajuda a fé, Lúlio apresenta a situação inversa antes do já citado trecho da Disputació sobre les Sentències de Pere Llombar: "Fides est instrumentum et juvamentum ut intellectus intelligat Articulos, ut legitur: 'nisi credideritis, non intelligetis'". ${ }^{31}$

A maneira como funcionam os mecanismos dessa mútua ajuda é um tema que não nos corresponde discutir agora. Basta que lembremos que o homem é criado principalmente para usar as três potências de sua alma para entender, amar e recordar a Deus. ${ }^{32}$

Retomando o fio dos nossos argumentos, vimos como Lúlio na sua pregação ad extra, isto é, sob a rubrica da "disputació", opõe autoridades à razão. Vejamos agora como se comporta com relação à pregação ad intra. Aqui a situação é tanto ou mais dramática. Os sermões da Idade Média (como hoje em dia) vinham construídos sobre citações bíblicas. Lúlio não desconhecia o fato, porque no prólogo do seu Llibre de virtuts e de pecats afirma que "A tot sermó pertany tema de la sacra Scriptura. ${ }^{33}$ Todavia, esta afirmação nos vem dada numa obra que contém 136 sermões, nenhum dos quais é construído sobre um tema bíblico! Como faz para resolver tal contradição? Simplesmente dizendo a seguir que o seu thema é o preceito geral dado por Deus a Moisés, a terceira das três frases citadas no início deste artigo: "Ama a Deus teu senhor com todo o teu coração, com toda a tua alma, com todo 0 teu pensamento e todas as tuas forças..$^{34}$ Logo a seguir esclarece que "aquest manament es general a tots particulars manaments, e per ço d'aquest manament entenem culir les temes d'aquest libre." (este mandamento é geral e inclui todos os mandamentos particulares, e por isso dele extraímos os temas deste livro.) $\mathrm{E}$ é este "manament" ou "precepte" ${ }^{\prime 35}$ que justifica a antes denominada "primera entenció", e conseqüentemente abre a porta à razão ${ }^{36}$ Quando Lúlio fala de razão, refere-se à sua Arte, que é a sua maneira de estruturá-la e apresentá-la, o que lhe permite escapar dos themata habituais dos sermões, e construir o Llibre de virtuts e de pecats com os mecanismos combinatórios, aqui aplicados exclusivamente às virtudes e aos vícios. ${ }^{37}$ Destarte está seguindo a linha já traçada no Blaquerna, onde nos tinha explicado que

31 Com respeito a esta segunda das três frases tão citadas, cf. a nota n. 5 acima.

32 É por isso que os atos das três potências da alma, representados pela Figura S, têm tanta importância na etapa quatemária da Arte.

Numa versão simplificada, como corresponde a um público não necessariamente instruído. Cf. ROL XV, pp. lxxvi-lxxvii, para uma descrição dos mecanismos utilizados, que têm uma certa semelhança com a combinatóna de virtudes utilizada no Llibre del gentil e dels tres savis. 
"A preycar era útil cosa provar per ranons naturals la manera segons la qual vertuts e vicis són contraris, ni com una virtut se concorda ab altra e um vici ab altre, ni per qual natura pot hom mortificar un viçi $a b$ una virtut $o$ ab dues, ni com una virtut pot hom vivificar $a b a l-$ tre; e aquesta manera és en la Art abrevyada d'atrobar veritat. ${ }^{\text {"38 }}$

Lúlio, numa outra obra, opõe claramente esta pregação per moralem philosophiam à outra, per authoritates, e questiona qual das duas é a melhor. A resposta, que não toma partido por nenhuma das duas, é que "són dues les terres en les quals es sembra la predicació: en una brota la intel-ligència, i en l'altra la creença." ${ }^{39}$ Todavia, na Ars generalis ultima oferece outra resposta, mais contundente. Diz que o pregador deve atuar deste modo na sua pregação, "perquè per tals coses, l'enteniment dels que l'escolten és més ferm per entendre que per creure autoritats dels sants, puix que en creure l'enteniment opera fora del seu acte natural, que és l'entendre. ${ }^{1140} \mathrm{Em}$ outra obra explica a afirmação de que a teologia é ciência em dois sentidos, "un apropiat, segons la fe donada per Déu, i la propia, perquè a l'enteniment no és propi creure, sinó entendre. ${ }^{141}$ Novamente opõe fé e entendimento, pondo este último como "primeira intenção".

Antes de abandonarmos o tema da pregação luliana, precisamos mencionar só de passagem, pois a sua discussão a fundo exigiria outro artigo - os únicos contraexemplos notáveis à ausência de themata. São os sermões do Liber de praedicatione ou Ars magna praedicationis de 1304 e o Liber praedicationis contra Judaeos de $1305 .{ }^{42}$ Como demonstrou um estudo recente, este fato teve sua justificação numa nova técnica com a qual o beato intenta "reduir" ou "aplicar" as citações bíblicas às suas razões necessárias, "perquè les autoritats no són contra la raó, quan són veres..." (dado que as autoridades não são contrárias à razão quando são verdadeiras... $)^{43}$ Mais tarde, no Llibre de virtuts e de pecats, em seqüência à passagem citada acima, afirma que "als sermons qui(s contenen en est libre poden esser

38 Blaquerna, cap. 93 (ENC 58-59, 241), citado por Domínguez em ROL XV, p. xliii. "É útil na pregação provar por razỏes naturais o modo segundo o qual as virtudes e os vícios são contrários, e como uma virtude concorda com outra, ou um vício com outro; e por qual força pode-se mortificar um vício com uma ou duas virtudes, e de que maneira uma virtude pode vivificar uma outra. E estes procedimentos encontram-se na Arte abreviada de encontrar a verdade."®

39 "Quaestio. Utrum praedicatio sit major per authoritates quam per moralem philosophiam? Solutio. Duae sunt terrae in quibus seminatur praedicatio: de una oritur intelligentia, et de altera oritur credentia." Lectura super Artem inventivam et Tabulam generalem (MOG V, $713=$ Int. v, 355), citado por Dominguez em ROL XV, p. xlvi.

40 "Praedicator sic debet agere in praedicando, sicut facit intellectus in inveniendo ea de quibus scientia est. (...) Nam per talia intellectus audientium firmior est per intelligere quam per credere auctoritates sanctorum, eo quia in credendo intellectus agit extra suum actum naturalem, qui est intelligere; nam unumquodque magis gaudens et contentum est, quando suo proprio actu uti potest." ROL XIV, 386.

41 "Respondit Raymundus dicens, quod teologia sit scientia duobus modis, scilicet appropriate et propie; appropiate, secundum fidem a Deo datam (...) et est scientia proprie, quia intellectui no est proprium credere, sed intelligere." Disputatio eremitae et Raymundi super aliquibus dubiis questionibus Sententiarum Petri Lombardi, MOG IV, 226 = Int. iv, 2.

42 O primeiro publicado em ROL III e IV, e o segundo em ROL XII, p. 1-78.

43 Thomas E. Burman, "The influence of the 'Apology of Al-Kindi' and 'Contrarietas alfolica' on Ramon Lull's Late Religious Polemics, 1305-1313", Mediaeval Studies 53 (1991), p. 197-228. À página 218 cita a passagem do Liber de fine (ROL IX, 259) traduzido aqui. 
aplicats tots sermons qui sien de la sacra Scriptura culits." ${ }^{144}$ Assim encontrou um modo simples de subordinar as themata homiléticas aos seus procedimentos artísticos.

Concluindo, Raimundo Lúlio, quer na pregação ad extra, quer na ad intra, troca as auctoritates pela razão, e até mesmo quando cita alguma, é porque encontrou uma maneira de aplicar-lhe as suas razões. $\mathrm{E}$ as suas razões - e isto o conhecemos bem pois sempre o repete - encontram-se sempre na Arte, num subconjunto da Arte, ou se derivam dela. É nesse aspecto que a obra do beato se diferencia dos outros intentos realizados na Idade Média para provar mais racionalmente a existência de Deus ou de alguns ou de todos os artigos da Fé. Se começa - sobretudo no Llibre de contemplació - com o fides quaerens intellectum de Santo Anselmo, logo se afasta dele, não no sentido de abandonar esta procura, que de fato nunca abandonará, mas no de integrar esta busca num sistema autônomo e muito mais geral. O mesmo poderia dizer-se da distância entre o sistema luliano e o notável De arte catholicae fidei de Nicolau de Amiens, ${ }^{45}$ que foi citado como seu possível precursor, ${ }^{46}$ ou as Regulae de sacra theologia de Alà de Lilla. ${ }^{47} \mathrm{O}$ beato propõenos uma ciência das ciências, um mecanismo em torno do qual possamos agrupar, estudar e explicar todos os outros conhecimentos. Além disso, sempre o faz olhando para dentro, isto é, fazendo referência ao coração artístico de sua obra. Não quer que nos distraiamos olhando a través da janela para a paisagem dos outros pensadores; repete-nos uma e outra vez que a solução se encontra aqui mesmo, neste cômodo isolado do mundo exterior, mas dentro do qual encontraremos todas as ferramentas intelectuais (e espirituais) que precisamos. Desta maneira propõe-nos um sistema que poderíamos chamar endoreferencial, em vez de um outro exoreferencial, como era costume na época. Quer dizer, um sistema baseado numa intertextualidade interior.

Contudo, torna-se necessário que nos perguntemos o que pretende com tal programa. Penso que podemos descartar, por motivos evidentes, o motivo do egoísmo. Penso também que é preciso pôr de lado a inocência do principiante, cuja originalidade provém do desconhecimento do que acontece à sua volta. Talvez aconteceu-lhe algo parecido na sua primeira viagem a Paris, onde esbarrou de um modo muito desagradável, como narra a Vida coetanea, com "el comportament dels escolars" e "la fragilitat de l'enteniment humà." ${ }^{48}$ Todavia, já na segunda viagem, vai preparado para convencer o mundo universitário. Nestes dois anos de 1297 a 1299 escreve três obras com a finalidade de demonstrar que a sua Arte pode-se aplicar na resolução das questões que se discutiam: eram a Declaratio

44 NEORL I, 10. "todos os sermões tirados da sagrada Escritura podem ser reduzidos aos sermões contidos neste livro" $\otimes$

45

46 Etienne Gilson, La philosophie au Moyen Age (Paris, 1947), p. 462.

47 Ed. N. M. Häring, "Magister Alanus de Insulis, Regulae caelestis iuris", Archives d'histoire doctrinale et littéraire du moyen àge 48 (1981), p. 97-226. Cf. o fundamental trabalho de Charles Lohr, "The pseudo-Aristotelian 'Liber de causis' and Latin theories of science in the twelfth and thirteenth centuries", Pseudo-Aristotle in the Middle Ages (Londres: Warburg Institute, 1986), p. 53-62, com relação ao lugar destas obras na história do pensamento cientifico e teológico.

48 OS I, 30 . 
Raymundi per modum dialogi edita que tratava dos 219 artigos condenados pelo bispo de Paris em 1277, a já citada Disputació sobre les Sentències de Pere Llombard, que tratava das questões em que se fundamentava o ensino na Faculdade de Teologia, e o Liber super quaestiones Magistri Thomae Attrebatensis, que sempre me pareceu uma espécie de teste que impôs ao seu novo discípulo, Tomás le Myésier, para verificar se o sistema luliano era capaz de manter-se em pé na capital intelectual da Europa. ${ }^{49}$ Ao mesmo tempo escreveu outras três obras para demonstrar a aplicabilidade do seu sistema às ciências, talvez com a finalidade de convencer a Faculdade das Artes: eram o Tractat d'astronomia, o De quadratura e triangulatura de cercle e o Liber de geometria nova et compendiosa. Também produziu uma nova versão do seu sistema para fundamentá-lo completamente: a Ars compendiosa (ou Brevis practica Tabulae generalis). ${ }^{50}$

Revisando novamente a segunda destas obras, a Disputació sobre les Sentències de Pere Llombard, penso que podemos esclarecer o intuito do beato. No prólogo da obra, diz-se que "Ramon, mentres que estudiava a Paris i considerava l'estat pervers del món, es dolia fortment, principalment del fet que ell, amb l'Art general que Déu li havia donat a fi d'il-luminar les tenebres d'aquest món, encara no havia pogut moure el govern de l'Església de Crist, tal com volia." Perto do rio Sena encontrou um ermitão, estudante de teologia, que se queixava pelas dúvidas e dificuldades que encontrava nas questões das Sentències de Pere Llombard que estava lendo. Lúlio ofereceu-se para ajudá-lo com uma "certa Art general que Déu m'ha mostrat en una muntanya, amb la qual, de bon grat, per a l'honor de Déu i la teva pau, intentaré resoldre les teves qüestions. ${ }^{1{ }^{11}}$ Por duas vezes, pois, afirma que a Arte é um dom de Deus. Trata-se de uma afirmação que repete em muitas obras, $e$ que representa um dos momentos chave da Vida coetanea.$^{52}$ É evidente que para Raimundo Lúlio, o fato deveria ter uma importância decisiva, mas para nós, no sé-

49 Como observou com razão Ruiz Simon, nunca deixa de responder às questões que colocam seus contemporâneos, todavia habitualmente o faz de um modo algo escondido, năo defrontando abertamente as questiones disputatae do momento.

50

Sobre as edições destas sete obras, cf. OS I, 559-561, ao qual deve-se acrescentar as edições novas do Tractatus novus de astronomia e da Declaratio Raymundi per modum dialogi edita, publicadas em ROL XVI; e uma tradução francesa do De quadratura et triangulatura circuli obra da qual Armand Llinarès publicou uma parte, "Version française de la première partie de la 'Quadrature et triangulature du cercle'", EL 30(1990), p. 121-138, e a restante em Raymond Lulle, Principes et questions de Théologie, ed. Armand Llinarès, trad. René Prevost, "Sagesse chrétienne" (Paris, 1989).

51 "Raymundus Parisiis studens et considerans perversum statum hujus mundi, multum doluit et potissime super hoc quod ipse per Artem generalem, quam Dominus Deus illi dederat pro illustrandis tenebris hujus mundi, rempublicam Ecclesiae Christi nondum potuerit promovere, ut optabat. (...) [O ermitão diz que ele] Parisiis diu studuisset in Theologia, ut cum libris in quibus studuerat melius posset cognoscere et amare Deum (...) Veruntamen, inquit, quia in isto scripto edito super Libros sententiarum, quod nunc lego, invenio quasdam dubias et difficiles quaestiones, quarum veritatem non possum videre, sum valde afflictus in tantum quod in aliis veritatibus, quas intelligo de Deo, no possum quiescere. (...) Raymundus respondit: cogito de quadam Arte generali quam Deus mihi ostendit in quodam monte, cum qua libenter ad honorem Dei et tuam pacem tentabo solvere tuas quaestiones." MOG IV, $225=$ Int. iv, 1.

52 Cf. OS I, 23 n. 80, sobre os outros lugares da Vita coetanea e de outras obras onde fala de sua iluminação divina. Sobre a importância deste acontecimento, cf. Fernando Dominguez, "Idea y estrutura de la 'Vita Raymundi Lulii'", EL 27 (1987), p. 13. Cf. também Gabriel Segui Vidal, "La influencia cisterciense en el Beato Ramón Llull", EL 2 (1958), p. 249-250. 
culo $\mathrm{XX}$, soa a algo comprometido, desconcertante. Hoje, ser iluminado, não é bem visto. $\mathrm{O}$ termo até carrega certas conotações de desaforado ou endoidecido, e com Raimundo Lúlio, que em alguns círculos ainda continua sofrendo dessa reputação, a questão torna-se ainda mais vital. Todavia, se quisermos compreender o papel social, espiritual, pedagógico e apologético de Raimundo Lúlio no mundo de seu tempo, não podemos esquecer este fator, sem qualquer nervosismo pelas possiveis conotações de hoje.

Considerado assim, é lógico que numa sociedade como a cristã ou a muçulmana da Idade Média, como a da Índia de hoje, a iluminação era não apenas bem vista, senão que até tendia a fazer do receptor um objeto de veneração, uma personagem cujo ensinamento teria garantias de uma espiritualidade e sabedoria superiores. Para tornar essa idéia mais compreensivel no mundo acadêmico de hoje, ser iluminado naquela época era como hoje possuir a mais elevada titulação possível, o que tornava o iluminado uma nova auctoritas.

Mas a iluminação de Lúlio (falamos agora da iluminação de Randa e não da visão do Cristo crucificado que produziu a sua conversão nove anos antes) não consistiu numa visão divina ou numa experiência mística de união extática, senão que produziu-se quando "de sobte el Senyor il-lustrà la seva ment, donant-li da forma i manera de fer el llibre [...] contra els errors dels infeels." Em conseqüência disso, "començà a ordenar i escriure aquell llibre, que primer anomenà Art major i més tard Art general. Sota aqueixa Art escrigué després molts de llibres [...] en els quals explicava extensament els principis generals, aplicant-los als més especifics. ${ }^{153}$ Como fica bem claro, o que recebe na iluminação não consiste em algum tipo de consagração pessoal, mas numa "forma i manera" (ou "forma i mètode" formam et modum), quer dizer, a Arte, da qual ele será apenas o transmissor, ao plasmá-la e modificá-la num conjunto de livros de diferentes títulos. Esta escala de valores fica ainda mais evidente na crise de Gênova, onde, perante a necessidade de decidir entre a própria salvação (com os dominicanos) ou a da Arte (com os franciscanos), prefere salvar a "Art que li havia estat revelada a honor de Déu i a la salvació de molts. ${ }^{154}$ Desta maneira, no caso de Lúlio, a auctoritas residia na Arte, não na sua pessoa.

Com o intuito de compreender melhor como era interpretado isto entre "les mentalités" da época, e na questão da auctor-auctoritas que já estudamos, dispomos de um interessante mecanismo que nos permite comparar a atitude de Lúlio com a de seus contemporâneos. No século XIII espalhou-se um novo estilo nos prólogos aos comentários dos auctors, baseado nas quatro causas aristotélicas.$^{55} \mathrm{O}$ auctor era apresentado como a "causa eficiente" da obra que se comentava; o conteúdo - o substrato da obra - constituía a "causa material"; o seu estilo literário, seus métodos ou procedimentos, e a estrutura da obra estudavam-se sob a rubrica

53 "Subito Dominus illustravit mentem suam, dans eidem formam et modum faciendi librum (...) contra errores infidelium." "Coepit (...) ordinare et facere librum illum, vocans ipsum primo Artem majorem, sed postea Artem generalem. Sub qua Arte postea plures (...) fecit libros, in eisdem multum generalia principia ad magis specifica (...) explicando." Vita coetanea, § 14 (ROL VIII, 280-1; OS I, 23).

54 "Ars ad honorem Dei et salvationem multorum revelata." Vita coetanea, § 24 (OS I, 33; ROL VIII, 288).

55 Referimo-nos ao estudo de Minnis citado na nota $\mathrm{n} .13$ acima. 
da "causa formal"; enquanto que a finalidade última da obra, o motivo pelo qual fora escrita, o benefício que se podia obter com ela, considerava-se a "causa final" ${ }^{16}$

Ora, no prólogo da Lectura super figuras Artis demonstrativae, que é de fato um comentário sobre uma de suas próprias obras, Raimundo Lúlio nos diz que

"Com les altres cincies, l'Art té un causa quadruple, és a dir, l'autor, la forma, la matéria i el fi. L'autor es podria dir que és Déu, a la magnificència del qual l'Art està dedicada, mentres que l'autor immediat és un home vil i pecaminós que no té importància. La matèria són les figures i termes de l'Art mateixa. La forma es troba en el descens de l'universal cap als particulars, el qual descens consisteix en el discurs ordenat dels actes de l'ànima per mitjà de la mescla dels triangles de la Figura $\mathrm{T}$ en el termes de les altres figures. Aqueixa mescla ordenada dóna lloc al resultat desitjat, que és la necessària afirmació de la veritat o la negació de la falsedat. Això deim que és el fi d'aquesta Art. ${ }^{\text {"57 }}$

Torna-se necessário prevenir a tendência natural do leitor moderno a tomar as afirmações da autoria divina da Arte, e do caráter "vil e pecaminoso" do "autor imediato" "que não tem qualquer importância", como figuras literárias, e a segunda afirmação como originada simplesmente pela modéstia do beato. Na sua opinião, como vimos, a Arte era realmente um dom de Deus, e a diferencia abismal entre a perfeição do autor real e a sua própria imperfeição era um fato indiscutível. Assim sendo, neste texto apenas nos transmite a sua visão de sua própria realidade. E, de acordo com a importância que, como vimos antes, o povo medieval outorgava às auctoritates, o fato de posicionar-se como transmissor de uma obra do auctor divino condiciona de modo fundamental quer a visão de seu próprio papel, quer a visão que dele podiam ter seus contemporâneos. As suas pretensões, como vimos, iam além da conversão dos infiéis (embora esta continuasse ocupando o centro de sua missão vital); incluíam também a pregação ad intra, a reforma da cristandade e inclusive - como acabamos de ver na discussão havida junto ao rio Sena sobre as Sentències de Pere Llombard - a introdução de seus métodos artísticos na Universidade de Paris. Lúlio sabe perfeitamente que isso não será fácil, ${ }^{58}$ mas persiste, e no final consegue ver aprovada a sua Arte (na forma da Ars brevis) por quarenta mestres e bacharéis das faculdades de Artes e Medicina. Concluem que "dicta Ars seu scientia erat bona, utilis et necessaria," e que nela puderam encontrar muitos elementos para a sustentação da fé. ${ }^{59}$ Van Steenberghen comentou, há mais de vinte anos, que "la chose n'a rien de surprenant: Lull était un viellard sympathique et

56 Minnis, op. cit., p. 5 e 28-9. Nas p. 14-15 relata que entre os estudantes da faculdade de artes, este prólogo denominava-se accessus, entre os glosadores do direito romano materia, enquanto que entre os exegetas das sagradas escrituras era denominado introito ou ingressus.

57 MOG III, 205-6 - Int. iv, 102; cf. OS I, 64-5. "Como as outras ciências, a Arte tem uma quádruple causa, isto é, o autor, a forma, a matéria e o fim. Poderia dizer-se que o autor é Deus, a cuja magnificência a Arte está dedicada, enquanto que o autor imediato é um homem vil e pecador, que não tem nenhuma importância. A matéria é constituída pelas figuras e termos da própria Arte. A forma radica no descenso do universal para os particulares, que consiste no discurso ordenado dos atos da alma, realizado pela mistura dos triângulos da Figura T nos termos das outras figuras. Esta mistura ordenada produz o resultado desejado, que é a necessária afirmação da verdade ou a negação da falsidade. Dizemos que esta é a finalidade de esta Arte." $\otimes$

58 Cf. a nota 60 mais embaixo.

59 Reproduzido em MOG I, 109-110. Cf. H. Riedlinger em ROL V, 138-141, e J. N. Hillgarth, Ramon Lull and Lullism in Fourteenth-Century France (Oxford, 1971), p. 155. 
respectable, mais un autodidacte et un original; son enseignement n'était adapté ni aux cadres, ni au programme de la Faculté des arts, ${ }^{160}$ mas penso que o beato estava bem consciente disso. Até porque faz dizer ao ermitão, no fim da já tão citada Disputació sobre les Sentències de Pere Llombard, "Ramon, me explicaste muitas coisas boas e novas, coisas que nunca ouvira antes. Mas, dado que tens uma maneira (modum) diferente do utilizado pelos modernos mestres e eu estou habituado nos temas científicos à sua maneira, e em alguns aspectos me educaram contra as tuas opiniões, e não estou ainda acostumado nem habituado aos teus argumentos, proponho-me habituar-me a eles com diligência, e, conforme o sistema que me trouxeste, fazê-los concordar com os princípios da tua Arte."61 Por isso, parece-me que Raimundo Lúlio sabia perfeitamente que não conseguiria reformar 0 ensino nas faculdades parisienses; intentava apenas formar um grupo de discípulos ou de pessoas, dentro das faculdades, interessadas no estudo de suas obras. É importante salientar também que não buscava discípulos para reuni-los à sua volta, como fez Abelardo, mas para que estudassem a sua Arte.

Neste sentido, é significativo que no fim da obra aprovada, a Ars brevis, Lúlio, como já fizera em outros trabalhos, explica como se deve ensinar a Arte. Primeiro deve-se decorar o alfabeto, as figuras, as definições, as regras e a tabela, e depois, que o artista "declar bé lo text als escolans raonablement, e no-s lic ab les autoritats dels altres."162 Portanto, poderíamos dizer que o que Raimundo Lúlio parece ter conseguido na sua última estadia em Paris foi que um grupo de mestres e bacharéis, após o exame de sua Arte, a aprovassem como sendo uma espécie de auctoritas paralela.

Com isto podemos dar mais um passo interpretativo em frente, e falar da relação - desejada ou real - entre Raimundo Lúlio e seu público. O historiador canadense, Brian Stock, ao estudar a seita dos valdenses do fim do século XII em Lião, mostra que se tratava de um movimento reformista baseado nas interpretações bíblicas do fundador, Pedro Valdo. Stock, portanto, descreve a seita como uma "comunidade textual." ${ }^{163}$ As diferenças entre esta seita populista e os lulistas de um século e meio mais tarde são quase tantas como as semelhanças, contudo penso que o conceito de Stock pode ajudar-nos a compreender os objetivos do beato e certos movimentos lulistas posteriores. Se entendemos "comunidade textual" no sentido

60 Fernand van Steenberghen, "Raimundi Lulli Opera Parisiensia." EL 13 (1969), p. 95.

61 "Ait eremita: Raymunde, dixisti mihi plura bona et nova, quae nunquam audiveram; sed quia habes alium modum extraneum quam habeant moderni magistri, et ego sum habituatus in scientia secundum eorum modum, et in aliquibis opinionibus sum nutritus contra tuas, adhuc non bene assuevi nec habituavi tuas rationes; et ideo propono ipsas diligenter habituare et secundum tuum modum per quem ipsas mihi tradidisti, principiis tuae Artis concordare." MOG IV, $342=$ Int. iv, 118 . Cf. o comentário de V. Hösle a esta passagem em Raimundus Lullus. Die neue Logik - Logica nova, ed. Charles Lohr (Hamburg: Felix Meiner Verlag, 1985), p. Ix.

62 OS I, 598, "mostre aos alunos o texto, seguindo os passos racionais, e não se apegue à autoridade dos outros" $\otimes$; ROL XII, 253; um texto similar pode-se encontrar em Ars generalis ultima, ROL XIV, 524.

63 Cf. o seu Listening for the Text. On the uses of the past. (Baltimore: Johns Hopkins University Press, 1990), principalmente os caps. 1 e 7, e também o seu "History, Literature, and Medieval Textuality", Images of Power. Medieval History/Discourse/Literature, "Yale French Studies" 70 (New Haven: Yale University Press, 1986), p. 7-17. 
mais amplo de um grupo de pessoas que centra as suas idéias fixas, intelectuais e espirituais, na interpretação ou no estudo de um grupo definido de textos, talvez nos aproximemos do que Lúlio intentava fazer. Em vez de propor uma nova interpretação do texto sagrado, ${ }^{64}$ como era corrente entre as seitas mais ou menos heterodoxas, Raimundo Lúlio propunha como objeto de estudo uma nova auctoritas: a Arte que Deus lhe dera.

A idéia de formar uma comunidade textual - ou diversas comunidades textuais - originava-se, como se sabe, do próprio beato, com o desejo expresso no fim da Vita coetanea e no seu testamento do ano 1313, de deixar depósitos de livros em Paris, Gênova e Mallorca como centros de propagação da Arte. A história do sucesso, ou do fracasso, de grupos de lulistas nestes e noutros centros (como Valência, Barcelona e Pádua) durante os dois séculos posteriores à morte do beato, faz parte da história do lulismo. No entanto, o que parece inegável é a existência, nas gerações posteriores, de grupos de lullisti que se dedicavam ao estudo de uma ars lulliana. Assim os via o inquisidor Nicolau Eimeric na sua raiva persecutória, e assim os devia ver Jean Gerson em Paris quando fez decretar que se deixasse de ensinar aquela famosa ars.

Porque, como mostrou Brian Stock, querer estabelecer comunidades textuais paralelas às estruturas oficiais da Igreja era perigoso, mesmo tendo em conta que Lúlio não queria opor-se à Igreja. Propor a formação de uma comunidade textual, que não se apoiasse em nenhum outro auctor fora Deus através da mensagem da ars, e querer assim "mostrar ciència al poble", comportava grandes riscos. ${ }^{65} \mathrm{Em}$ primeiro lugar, tal empresa, pela sua auto-suficiência e pela sua proposta de métodos alternativos, ${ }^{66}$ não apenas formava uma comunidade intelectualmente e espiritualmente isolada da sociedade bien pensant, senão que pela sua atitude aberta ou implicitamente crítica dos poderes públicos e da Igreja, naturalmente iria suscitar a oposição destes estamentos. ${ }^{67}$

Além do mais, o fato de uma comunidade não querer apoiar-se nas auctoritates consagradas, e se voltasse para as próprias interpretações ou textos, sempre suscitou suspicácias por ser algo que podia escapar do controle clerical. Como comentou o inquisidor dominicano, Étienne de Bourbon, que nos conta a vida do

64 O fato de propor uma interpretação altemativa à oficial da Igreja, automaticamente marginalizou a missão de Pedro Valdo, o que o diferenciava notavelmente de Raimundo Lúlio, famoso pelo seu afã de unidade e de universalidade. Este afã, contudo, não foi compartido por todos os seus seguidores - como por exemplo os espirituais franciscanos valencianos do séc. XIV, cuja ânsia inclinava-se mais para o choque e a marginalização.

65 Sobre a expressão "mostrar ciência ao povo", que se origina no Llibre de virtuts e de pecats, cf. NEORL I, p. 16, ROL XV, p. 123, e a análise de Femando Domínguez na introdução deste último tomo, p. xlii e ss.

66 A oposição do inquisidor Eimeric às "razões necessárias" lulianas é bem conhecida. Outra figura importante da época, o teólogo da cúria papal, Agustí Triomf, denunciou fortemente sua presunção e incorreção (cf. Hillgartg, Ramon Lull, citado na nota 58 acima, p. 56; e o seu Readers and Books in Majorca, 1229-1550, 2 vols., Paris: Centre National de la Recherche Scientifique, 1991, vol. I, p. 202).

67 Era, como resulta evidente, a última coisa que teria desejado Raimundo Lúlio, que desenvolveu um esforço enorme e sincero para persuadir todos os estamentos da validez de sua missão. Mas este suporte institucional que procurava nunca chegou com a força necessária para contrarrestar tal oposição, ou, quando chegava, era de setores de por si suspeitos - como foi o caso do ministro geral dos franciscanos, Ramon Gaufredi, conhecido pela sua simpatia com os espirituais. Hillgarth, Readears and Books, I, p. 202, comenta que talvez os aliados the foram mais funestos que os inimigos. 
fundador dos já referidos valdenses, a sua missão officium apostolorum usurpavit. ${ }^{68}$ $\mathrm{O}$ fato de que a maioria dessas comunidades textuais medievais se dedicasse, de uma forma ou outra, a "mostrar ciència al poble", apenas servia para tornar o fato ainda mais suspeito. E não citar nem a sagrada Escritura, nem seus próprios mestres, é inaceitável para o outro inquisidor, Eimeric. ${ }^{69}$ Este queixa-se também de que os lulistas "não querem acreditar nos mestres em teologia, canonistas, legistas, prelados, cardeais, nem até no nosso senyor santíssimo, o Papa." Uma comunidade textual também chocava com outra estrutura social da Idade Média, a profissionalização e institucionalização do ensino e do estudo da filosofia e teologia. ${ }^{70}$ Esta nova classe clerical, como era de se esperar, mostrava ter pouca paciência com os de fora que se entremetiam em temas para os quais achavam que não estavam preparados. Étienne de Bourbon já acusava os valdenses de serem gente idiote et illiterati ${ }^{71}$ e Eimeric dizia que Lúlio era ignarus et scientia imperitus. ${ }^{72}$ Eimeric, ao final de sua vida, queixava-se amargamente pelo fato de que a oposição que encontrara nas suas campanhas contra este homem phantasticus et begardus, viera não de gramáticos, dialéticos, físicos, filósofos, geómetras, músicos, aritméticos, astrônomos, astrólogos, matemáticos ou teólogos, nem também de duques, governadores, condes, barões ou marqueses, mas de comerciantes, sapateiros, cordoeiros, alfaiates, pisoeiros, marceneiros, ferreiros, prateiros, tecelões, taberneiros e farmacêuticos. $^{73}$

Mas o lulismo seguiria o seu caminho com uma lógica inexorável. O primeiro passo fora a criação de um sistema endoreferencial, que excluía citações de autoridades anteriores. A auctoritas deste sistema residia numa Arte recebida de Deus, em redor da qual o autor (imediato) praticava uma espécie de intertextualidade interior. O segundo passo consistiu na formação de comunidades textuais que se dedicassem ao estudo e à propagação deste conjunto de obras, que quando não excluíam totalmente os textos consagrados, os utilizavam paralelamente com os lulianos. ${ }^{74} \mathrm{O}$ terceiro passo foi o exílio, realizado pelo establishment, destas comunidades suspeitosamente independentes e dificilmente controláveis. Até mesmo, quando Lefèvre d'Étaples e Charles de Bouvelles, no começo do século XVI, quiseram reformar ou combater o establishment escolástico medieval, utilizaram como instrumento este idiota et illiteratus que já se havia oposto a ele dois séculos antes. É com a imagem desta oposição, agora vista como positiva, que Raimundo Lúlio volta a entrar nos caminhos mais cêntricos do pensamento europeu. ${ }^{75} \mathrm{E}$ durante todo esse século e o seguinte o beato não deixará de ser visto como uma figura alternativa.

68

69

70

71

72

73

74

75

Cf. Stock "History" (n. 62 acima), p. 15.

Hillgarth, Readers and Books, I, p. 198 e n. 48.

Le Goff (cf. n. 10 acima).

Stock "History" (n. 62 acima), p. 15.

Hillgarth, Readers and Books, I, p. 198 e n. 49.

Ibid. p. 201 e n. 65.

O fato de que se acrescentem outros textos pseudo lulianos, não muda para nada esta situação. As obras espúrias sobre alquimia, cabala o a Imaculada (dos lulistas valencianos) utilizavam o vocabulário e operavam no mundo conceitual luliano, e podiam ser de igual modo endoreferenciais.

Giordano Bruno também o admirava como stultus et idiota (cf. Michele Ciliberto, La ruota del tempo. Interpretazione di Giordano Bruno, Roma, 1986, 84). 